\title{
The Important Embodiment of the Growth Care in Kindergarten Furniture Design
}

\author{
Lei Shi \\ Department of Environmental Design \\ Eastern International Art College \\ Zhengzhou University of Light Industry \\ Zhengzhou, China
}

\begin{abstract}
Since twenty-first century, pre-school education has been attached great importance, and the urban and rural areas have strengthened the popularization level. The pre-school education develops rapidly. The kindergarten is the major preschool education institution. It plays an important role in science teaching and happy education. For daily life and activities in kindergarten, furniture is indispensable and young children are closely associated to it. The kindergarten furniture design should take all elements into consideration, so that kindergarten furniture can be good friend of young children in their study and life and provide them growth care.
\end{abstract} care

Keywords-young children; kindergarten furniture; growth

\section{OVERVIEW OF GROWTH CARE}

\section{A. The Time Significance of Growth Care}

Human's life is bound to experience childhood, teenager, adolescent and then adult. For young children, their growth is expressed in many aspects. And it means to develop toward the maturity stage. The overall social environment has provided help to healthy growth of young children. Young children can play games in kindergarten, study knowledge in museum, and watch children's show in theater. These social activities are beneficial to the healthy growth and overall development of young children.

However, the rapid development of society has brought about some wrong concepts on growth care of young children, such as excessive care and absence of care. Under the education concept of "Don't let children lose at the starting line", a lot of urban young children are forced to go to various learning organizations. Children at a small age should carry heavy study pressure. However, in remote and poor areas, young children are completely unattended. Only a few receive pre-school education. These young children are lack of care.

Under the social background of promoting the harmonious development in the country, it is very necessary to give correct and appropriate growth care to young children, and it has the time significance.

\section{B. The Growth Care Can Improve the Life Quality of Young Children}

Bauhaus School pointed out: "design is for man rather than product". At the same time, Danish furniture design master Kate Barjigin pointed out: "things we made should have life, as if there is a heart beating in it. They should be vibrant, warm and humanized". 1

The design concept of "people first" reflect the basic care on users. Design should take full consideration of requirements of users, care bout the needs of users, correctly solve the relationship of people and things and make people use product in a natural state. It should not only start from the preference of designers, but also care the product function from the angle of people and the resulting social problems and care for the relationship of product and people from the perspective of anthropological self-consciousness.

Kindergarten furniture should first play the function of protection and assistance in young children's daily life. On this basis, it should play the role of positive care in improving the mind of young children. Furniture design should be centered on young children. Designers should intensively study the physical and psychological characteristics of young children, and find the highest level of design from the perspective of young children. With the care concept of people first, designers can really improve the quality of young children's life with their design.

\section{THE IMPORTANT EMBODIMENTS OF GROWTH CARE IN THE KINDERGARTEN FURNITURE DESIGN}

\section{A. Different Types of Kindergarten Furniture and the Embodiments of Growth Care}

1) Fixed-type furniture and its embodiment of growth care. Furniture is the content of the building space. The concept of architectural design can continue into the interior space, especially for public buildings. Indoor ceiling, wall, partition and furniture, as a whole, express the design elements. This kind of furniture mainly is fixed type. Fixed-type furniture is

\footnotetext{
${ }^{1}$ Qiu Zhicheng, Gao Juan and Li Huiping. Relationship of Humanistic Product Design and Reason. Package Engineering, 2005, (2): 188 - 189.
} 
an important part of the space, and it has the function of furniture "Fig.1".

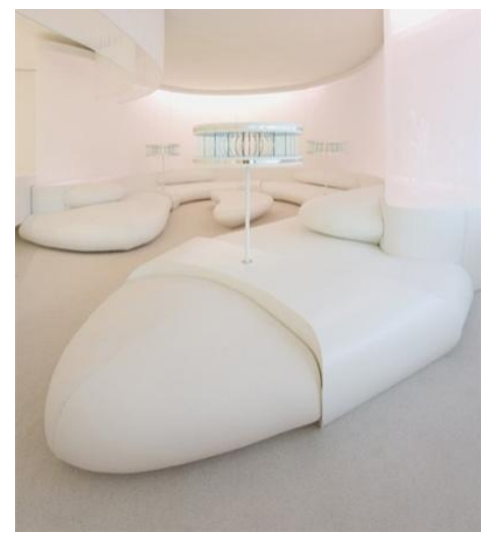

Fig. 1. German Leonard Glass Cube Interior Space Furniture

Various elements in building space integrate into one from top to bottom. Different colors, lights and ceiling elements create a colorful and ordered lighting effect. Smooth long seat is the continuation of ceiling, and is the place for children to read, discuss and play games. The functions of furniture can be changed or increased by making change in building size and shape. To improve the design of stairs in size and shape could bring space for children to communicate and play games "Fig. 3", "Fig. 4". Furniture relying on building construction mainly is fixed type. This type of furniture should be coordinated with indoor visual effect in function, style, colors and etc. Fixedtype furniture mainly is high, such as locker, wardrobe, and partition. Fixed furniture for kindergarten should take size into consideration, for it should meet the requirements of the body size of young children and satisfy the needs of young children.

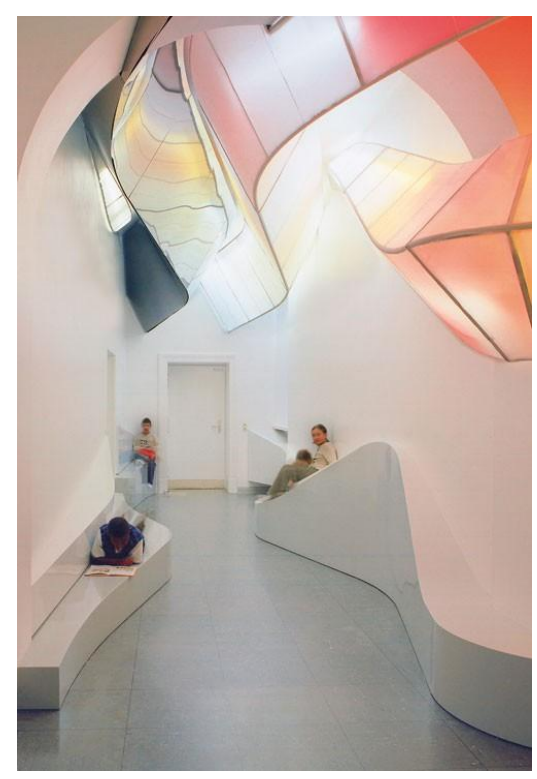

Fig. 2. A Foreign Kindergarten

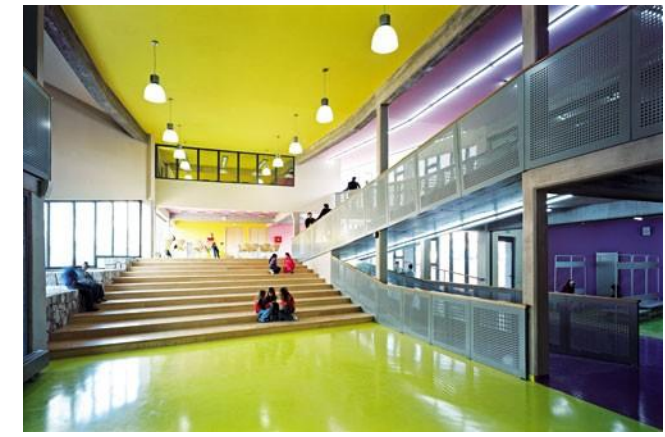

Fig. 3. Communication Space of a Foreign School

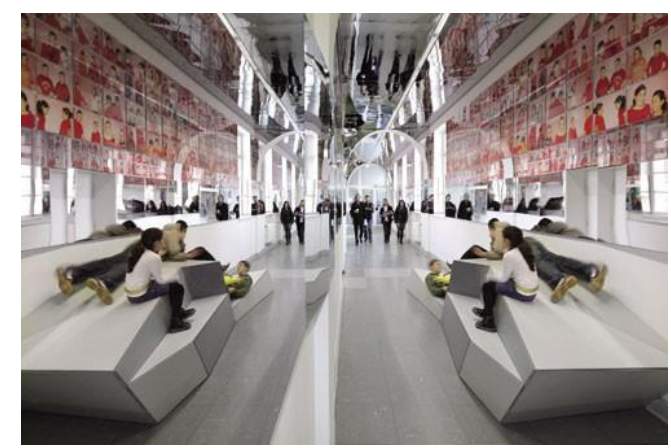

Fig. 4. Communication Space of a Foreign School

2) Mobile-type furniture and the embodiment of growth care. Mobile-type furniture refers to the furniture that can be moved freely or has castors at the bottom. In the kindergarten tables, chairs, cup rack, towel rack and clothes rack in kindergarten can be moved.

Users of furniture are young children from 3 to 6 . They are active and energetic, and collisions are inevitable, so kindergarten furniture should minimize the damage risk. For example, give smooth processing on the edges of furniture and eliminate sharp edges. The materials of furniture should be soft and warm in order to protect the safety of children "Fig. 5", "Fig. 6", "Fig. 7".

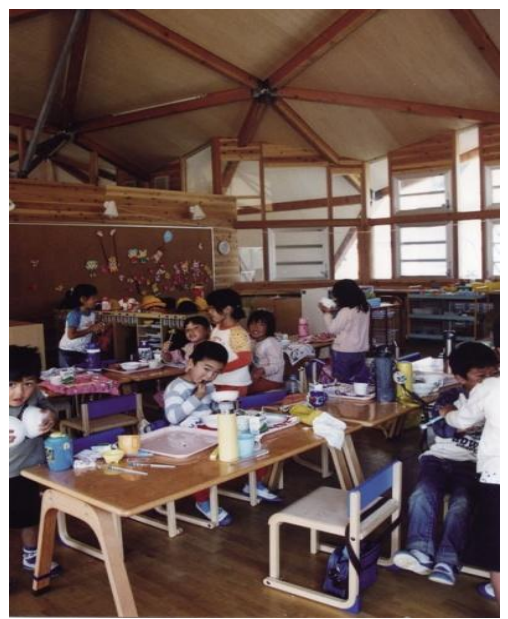

Fig. 5. Indoor Furniture of a Foreign Kindergarten 


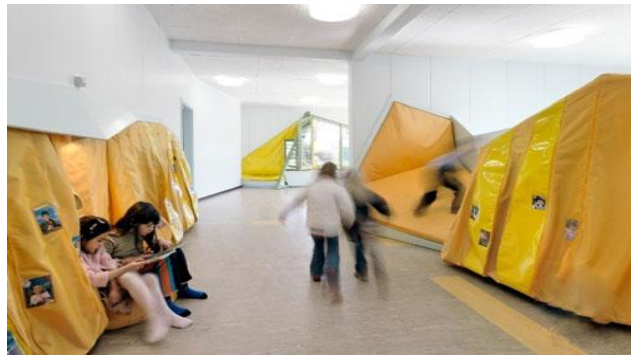

Fig. 6. Indoor Furniture of a Foreign Kindergarten

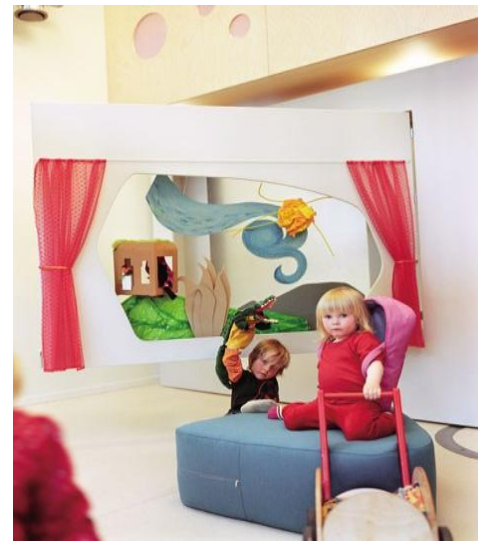

Fig. 7. Indoor Furniture of a Foreign Kindergarten

Children have plenty of imagination, and they are energetic and active. They always full of freshness. Children always try to move some objects, such as furniture and toys, and then rearrange them. They may move furniture, re-arrange a cushion, and enclose a small space with bed sheet. Designers should satisfy ideas and wonders of young children, so as to develop their imagination and intelligence. Therefore, kindergarten furniture shouldn't be too heavy to move in order to meet their aspirations.

\section{B. Kindergarten Furniture of Different Functions and the Embodiment of Growth Care}

1) Active-type furniture and the embodiment of growth care.

Advanced pre-school education concepts require designing some spaces for activities in kindergarten. These spaces can be small news and magazine stands, small clinic, small bus station and small families. It can help children to experience the role of life in these activity spaces. By performing these roles in activity spaces, children experience the fun of communication. In activities and games, they learn to communicate, think, and express themselves in different roles. It could promote the overall development of young children and help them become a whole man. The furniture in these activity spaces should be a little small in size in order to express the small concept and meet the needs of young children. In addition, these spaces should be equipped with tables, chairs, beds and etc "Fig. 8", "Fig. 9".
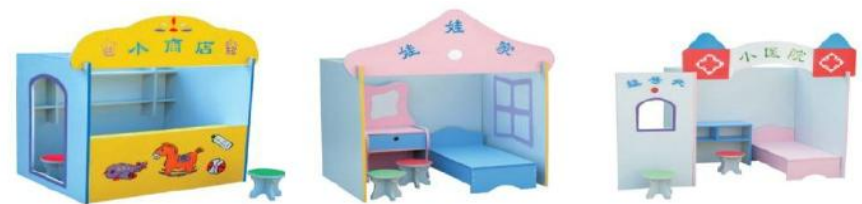

Fig. 8. Role Experience Activity Space of a Domestic Kindergarten

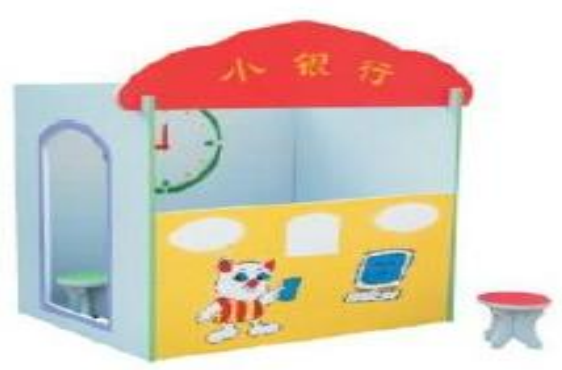

Fig. 9. Role Experience Activity Space of a Domestic Kindergarten

The following pictures are scenes of activities in an Israeli theme school. The furniture for activities is lively and free to move, which gives children a greater space to play "Fig. 10".

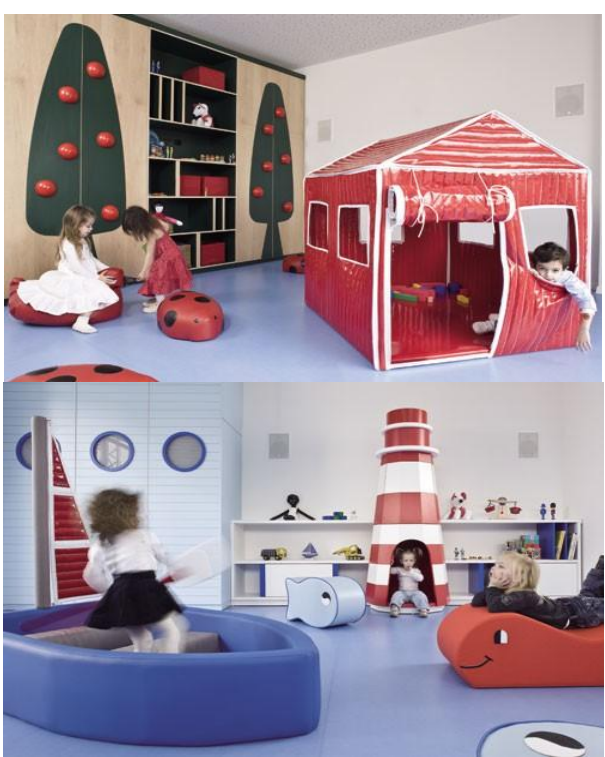

Fig. 10. Activity Scenes of an Israeli Theme School

It is the spy game space of Carl Bolle, a full-time school.

The corridor is converted into a leisure area, in accordance with the school's sports orientation. By creating new architecture and optical and acoustic space, children can play in the corridor. At same time, it is an interesting study in scientific observation environment. Children can also climb along walls, observe from different angles, or seek out a small space through a number of holes "Fig. 11". 


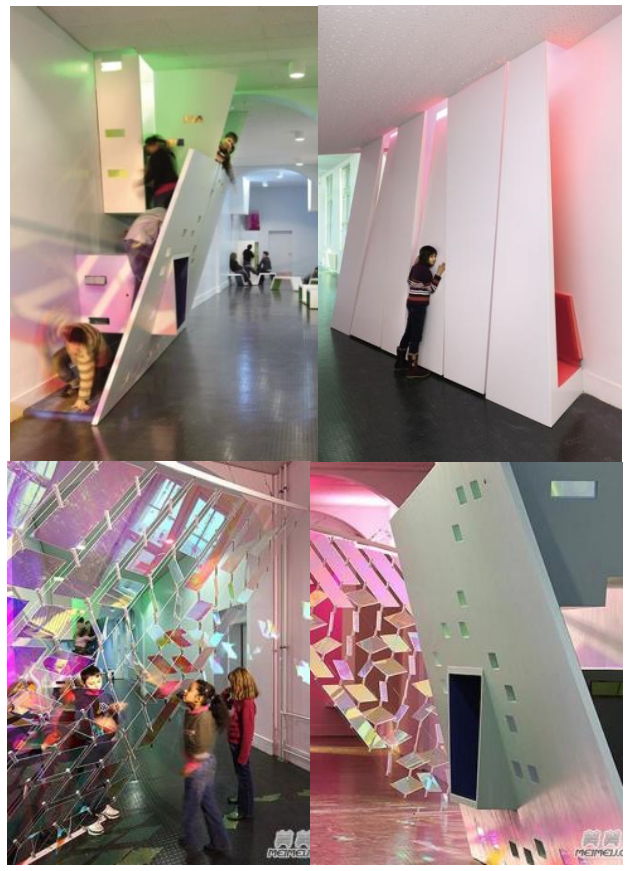

Fig. 11. The Spy Game Space of Carl Bolle Full-time School

2) The learning-type furniture and the embodiment of growth care. Kindergarten education mainly includes games and activities. The classes are not serious as that of elementary students, and are to give correct guidance in the freedom growth process of young children. But as the young children grow slowly, they learn simple knowledge from fairy tale books, story books and picture books. And these are important activities for them to learn new things and grow.

The learning-type furniture mainly includes tables, chairs, bookshelves, easel and etc "Fig. 12". Furniture in children's reading space shall be designed according to the size of children's body. Generally the bookshelves shall be within 1.2 meter height. The furniture arrangement shouldn't be too serious. It should be arranged freely, with the combination of various forms. At same time, set some scenes to help children read books, or practice listening, speaking and performance.

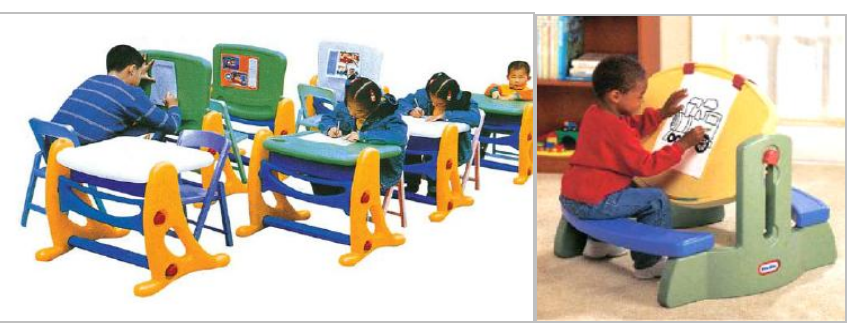

Fig. 12. Tables, Chairs and Easel in Kindergarten

For young children, learning is usually inseparable with play, so fun is very important in learning. Children can learn things in play. Beijing Pupulan Picture Book Library is such a space "Fig. 13". The first floor is a small activity space, which is "wrapped" by twelve ribbons of different colors and different perimeters, like a rainbow. This place can hold picture book reading, cartoon showings and other activities. The material is carpet, so children can sit or lie everywhere.
From the floor at the door of lift well, circular "rainbow" attracts children to the library at the second floor. Children can go upstairs and go downstairs along the rainbow, circling around the book store. Some places are bookshelves; some are tables and door openings; some are cashier desks. They are elements of the ceiling. This rainbow goes through 100 meters and then returns back to the handrail of staircase. There is no neatly arranged bookshelf. Children can read books at their favorite places. Arrange different sizes of circular openings close to windows, and create some cement-pipe-like reading places. Children's figures are also important elements of space design. The joyful scenes are clear at a glace.

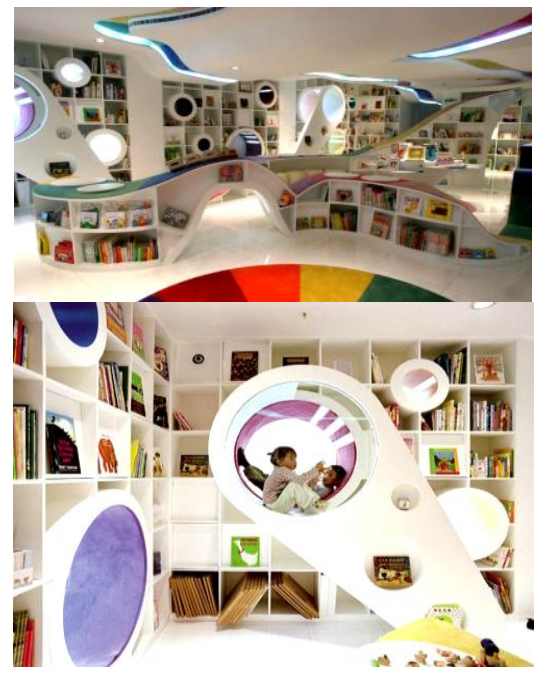

Fig. 13. Beijing Pupulan Picture Book Library

On the top floor of Metrople Mall in Denmark Hjorring, three children are telling stories to their friends in the green "listening tree" and the others are jumping on the foam pad near the "tree". A mother is playing games with children. In the blue and orange opening holes on the wall, a boy is calling his friend near him "Fig. 14".

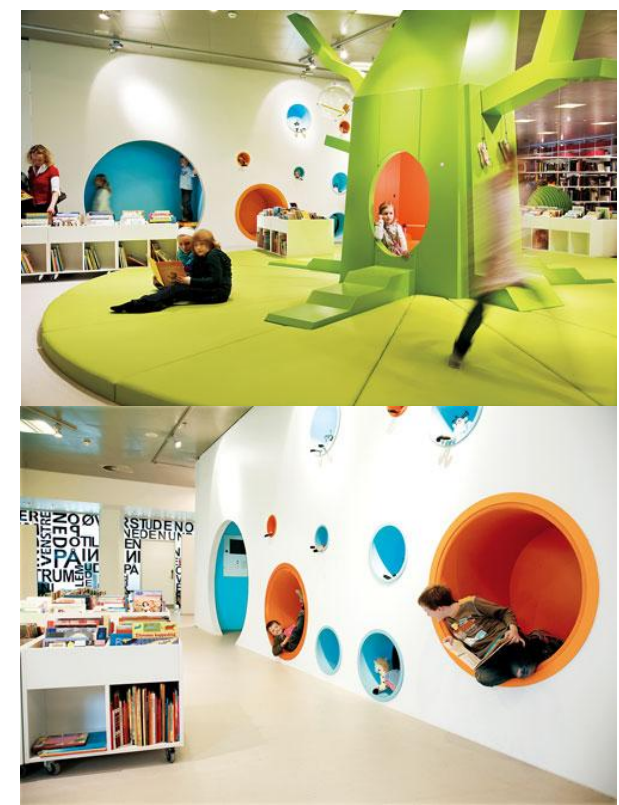

Fig. 14. Interior of Metrople Mall 
3) Lifestyle furniture and the embodiment of growth care. The lifestyle kindergarten furniture mainly includes children bed, cup rack, towel rack, locker, toy cabinet and etc. Young children have three hours of midday rest at daytime. The researches of medical and psychological field show that good sleep promotes the growth of children. Environment creation and furniture arrangement in rest area are very important. The bedroom shall be quiet and not directly blown by wind. Children do not need sunshine at sleep time. But at other times, the bedroom shall be shined and ventilated. Activity room can connect with bedroom horizontally or vertically.

The National Nursery and Kindergarten Building Design Code requires that the bedroom area and activity area for each class shall be at least 50 square meters in Kindergarten. In reality, kindergartens can not reach to this standard due the lack of land resource. Young children only use bedroom when they have midday rest. Under the premise to guarantee the use function, it is a good idea to make overall design on the furniture and space form in order to improve the utilization rate of the space "Fig. 15".
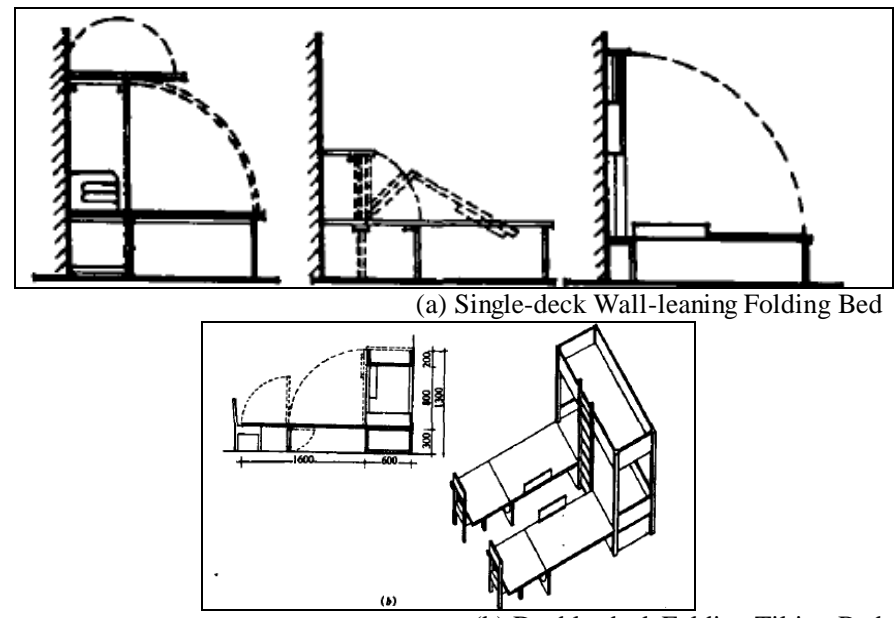

(b) Double-deck Folding Tilting Bed

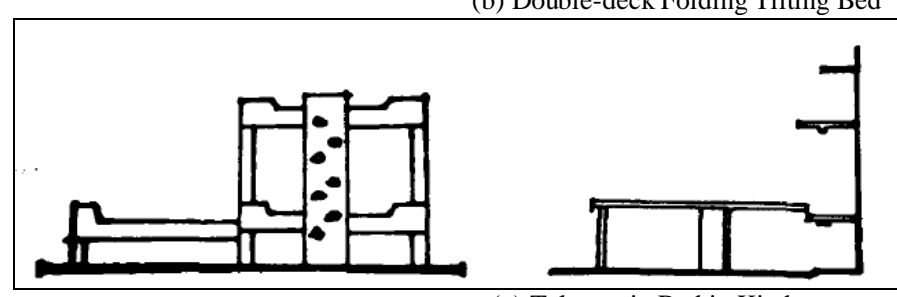

(c) Telescopic Bed in Kindergarten

Fig. 15. Multi-function Beds in Kindergarten

In bedroom design, we can use various segment forms and combine changeful activity rooms and rest rooms under the condition to meet the size of young children. In this way, we use limited space effectively and make space full of fun. With safe environment for young children, we explore the multifunction of space "Fig. 16".

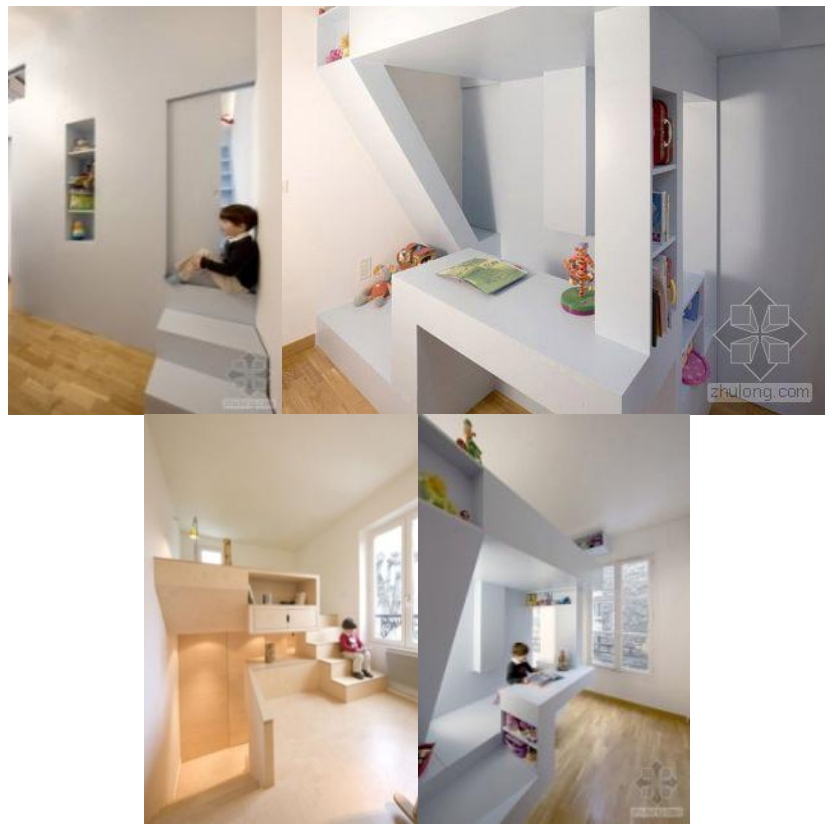

Fig. 16. Overall Design of Children Bedroom

Other lifestyle furniture designs should also meet the size of children, and meanwhile they should reflect the interestingness and identifiability of furniture, and the versatility of material, and make children's living space full of beauty "Fig. 17".

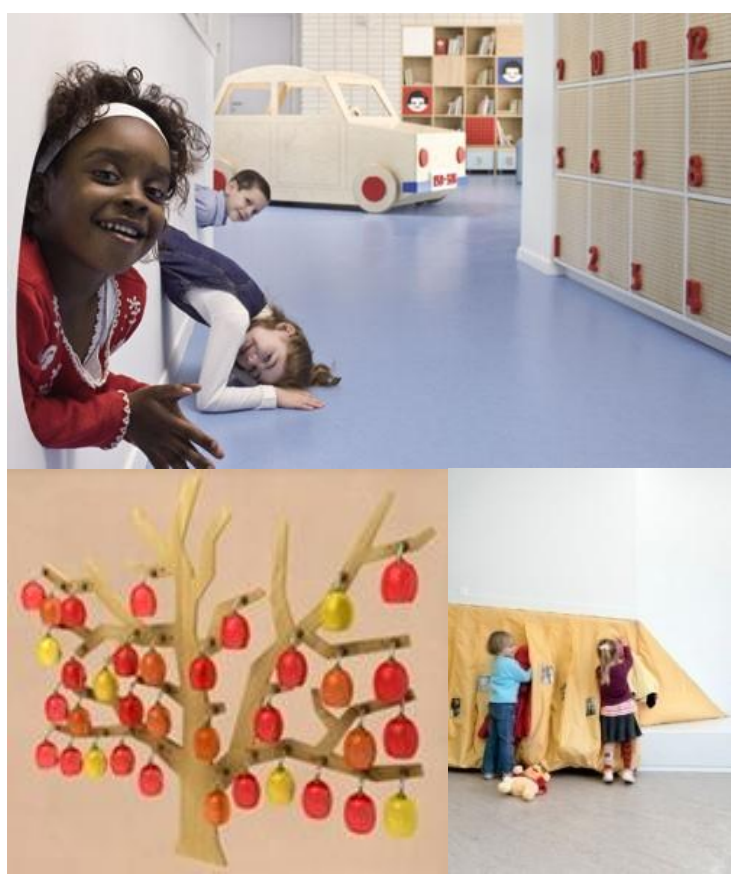

Fig. 17. Lockers, Wardrobe, Cup Rack and other Lifestyle Furniture in Kindergarten

\section{The POSITIVE IMPACT OF GROWTH CARE IN THE KINDERGARTEN FURNITURE DESIGN}

Children are growing in body and mind, and they belong to the vulnerable group of the society. It is social responsibility to 
give them care. They are weak and lack of self-protection awareness, so they need the society to give them material and spiritual care and thus grow in a safe and healthy environment.

The care concept based on the growth of young children has a positive guiding significance in the kindergarten furniture design.

The basic concept of social harmonious development requires social circles to give children basic care. This kind of care cannot only stay in giving them adequate food and clothing, providing existing space for them, or letting them have music, dance and painting classes regardless of their preference. These cares are out of the concept of grown-ups, and are so-called actions to love children. However, what they really need and how to express love and help children grow happily are problems we should seriously think about.

In the growing process of young children, the society, the preschool education institutions and the family should give them care and love in accordance with the concept of people first, and give correct help and guidance. It has a positive influence on the growth of children. The people-oriented care is to start from children themselves, understand their physical and psychological characteristics, and growth needs. From the perspective of children, we can really give healthy care to children in their growing stage.

This growth care concept is suitable for children's education and kindergarten environment. The kindergarten furniture in this paper has more direct impact. Active-type furniture, learning-type furniture and lifestyle furniture are classified according their functions. Designers can carry out design according to different functional requirements. All furniture has its unique functional requirements. Designers should start from the angle of children, and fully consider the demands of the children to express humanistic concern on the growth of young children and fully embody the growth care of kindergarten furniture on young children.

\section{REFERENCES}

[1] Chen Zujian. Common Furniture Design Collection. Beijing: Chemical Industry Press, 2008.

[2] Wang Zhenyu. Developmental Psychology of Preschool Children. Beijing: People's Education Press, 2004.

[3] (US) Donald A Norman, Fu Qiufang. Emotional Design. Beijing: Electronic Industry Press, 2005.

[4] Paco Asensio, Liu Peishan. Typical Design Examples of World Kindergartens. Beijing: China Water Conservancy and Hydropower Press, 2003.

[5] Li Wei. Research on Indoor and Outdoor Space Environment Design in Kindergarten. Chengdu: Southwest Jiaotong University, 2009.

[6] Li Jie, Rao Jing, Wang Juan. Discussion on Children's Furniture Design. Journal of Jingdezhen Junior College, 2006, (12): 88 - 89.

[7] Zhou Zewo, Design of Majadahonda Kindergarten in Madrid. Times Architecture, 2010, (5): 122 - 127. 